\title{
Discussion on How to Innovate Experimental Teaching of Landscape Design*
}

\author{
Xiaoyan Weng \\ Huanggang Normal University \\ Huanggang, China
}

\begin{abstract}
Landscape design course in China is mainly offered in major colleges including agricultural and forestry colleges, building colleges and art colleges. This article mainly studies the experimental teaching of landscape design offered in art colleges, discusses problems existing in the current experimental teaching, and tries to conduct reforms and exploration on teaching contents, methods, means and evaluation modes so as to achieve an ideal teaching effect.
\end{abstract}

Keywords-landscape design; experimental teaching;
innovation

\section{INTRODUCTION}

Nowadays, landscape specialty in art colleges is based on the original indoor design or environment and art design specialty. Compared to the Occident, the landscape design specialty is still a newborn in this country, especially in the current stage where the economy is in a rapid development, the landscape design specialty itself needs continuous renewal and adjustment. As one of the core course of landscape design specialty, the landscape design is highly professional and practical. Currently the experimental teaching of landscape design is still in exploration, and this article analyzes main problems existing, which include the following:

\section{SEPARATION FROM BASIC COURSES}

Landscape design is a highly comprehensive course and students are required to have solid basic knowledge to well master it. Yet for art colleges, most students have no basic knowledge relative to plant cultivation and garden architecture, besides, within the talent training program, there is only plant landscape offered which is related to botany, meanwhile, it is focused on plant morphology, having no knowledge of plant habits and cultivation. As for the architecture, there is only elementary architecture or garden architecture as optional course for basic knowledge of architecture, in addition, students of art generally feel it difficult to learn, meanwhile, due to lack of understanding, most students have ignored the structure of basic knowledge of architecture, which has caused differences of students in the basic knowledge.

*This article is a teaching study project of art and design experimental teaching demonstration center at Huanggang Normal University: Studies on innovation of landscape design experimental course through project teaching method.

\section{OLD TEACHING METHODS FOR EXPERIMENTAL COURSES}

Currently in most of traditional professional colleges, theoretical teaching is still a main pattern, which has no corresponding practical teaching, even experimental courses are still limited to traditional teaching pattern, the teaching methods are out of date and abstracted and experimental projects are completed simply through assignments, which causes the separation of teaching from assignment and failure to combine theories and practice, it lowers students' enthusiasm in learning, unable to reach the teaching effect as expected. Besides, most experimental projects are completed by individuals, students are in the lake of special training and teamwork, finally, and the works designed students are generally in a low quality.

\section{LACK OF EFFICIENT CONTROL OVER PROCESS, IRRATIONAL EFFECT EVALUATION}

Teachers only teach basic knowledge before experiment and there are no efficient controls over the process after completion of experimental projects, each student will complete the experiment alone, with the drawings handed over after completion of the experiment, they just get a score as final feedback, and teachers only give instruction during the course of the experiment, due to limited class time, many experiment projects as well as many students with different basic knowledge, teachers' instruction generally cannot work well, though some spend a long time completing the works, yet they know little of advantages and disadvantages of the works and key points for the future, in addition, some just directly copy others' programs. Seen from the whole experimental teaching, the instruction that teachers provide to students are inadequate, which makes it difficult to achieve the teaching goal as expected.

Aiming at the above problems, we can conduct the following innovative reforms:

\section{A. Integrate and Optimize Course Contents}

On the one hand, as far as theoretical knowledge, the basic knowledge that has been taught in experimental courses should go through the first stage of teaching, properly add analysis and interpretation of classic cases, take teachers' analysis as leading, then take a group as a unit to discuss cases, 
and make theoretical knowledge go through the case analysis, key points shall be stressed in the comprehensive application of theoretical knowledge, with the professional knowledge taught, the students are trained capable to find and solve problems

On the other hand, the setting of experimental projects shall consider the market demand and actual conditions of students, small space designs are recommended such as small theme square design, small park design, landscape design of residential areas, waterside landscape design and so on. If teachers have real projects, it can be temporarily adjusted and introduced to the class so as to rapidly improve students' design skills.

\section{B. Diversity in Teaching Patterns}

\section{1) Multimedia teaching}

Whether theoretical teaching or experimental projects, teachers may prepare many classic pictures and knowledge points, simple analytical characters, and multimedia tools with a lot of information such as pictures and characters can be used for teaching, which can bring students visual learning process and raise their interesting and efficiency. In the meantime, teaching modes are flexible such as asking questions freely, speaking what they think, competing to answer, modifying and makeup, discussing by group and so on so as to stimulate students' initiatives and activities to learn.

\section{2) $3 D$ on-the-spot teaching}

To teach students knowledge of landscape design in class is far from adequate, and on-the-spot teaching modes can be adopted, move the class to urban green land parks (as street park, botanical garden, communities, urban parks, gardens and so on) where designs and constructions are mature, and students are put in a 3D world with excellent landscapes to combine $2 \mathrm{D}$ drawings in minds to $3 \mathrm{D}$ real scenes, and the students will be trained to well grasp the space atmosphere and size so as to freely use what they have learned, with students feeling organs and stimulations activated, it will be much easier to expand their thoughts and taste the connotation of designs. Facing such a teaching environment, the students can not only master common plant variety, aspect change, appreciation characteristics, matching arrangement, but also conduct a practical learning on the landscape design, so that teachers can well control the teaching effect and quality, which will place a solid foundation for the follow-up experimental projects.

\section{Project Method Going through the Whole Experimental Project}

For the experiment course that is landscape design, the process of the experiment project is quite important, whose quality will directly influence the whole course effect. We can complete it by group through project method. The project can be real or visual through combining teaching and practice. We arrange to simulate the bidding process, establish a temporary group with 5-6 members for the same theme, carry out discussions and studies on the project, and dispatch tasks to members, students are required to look up and collect relevant data, participate in the design, each group shall establish a design program. In the classroom, every student is a bidder and bidding judge, first of all, the group representative shall introduce the program of its own through PPT, then teachers instruct students for analysis and discussion, and the program analysis shall be conducted deeply and carefully. Finally teachers will make a summary, which will help to strengthen students' abilities of analyzing and solving problems and foster students' thinking habits open and critical. Students can directly learn design methods and also understand rules of actual project operation; meanwhile, it helps to cultivate the teamwork awareness and abilities. On the other hand, with the project method going through the whole experiment project, the project implementation course is well controlled, the whole experiment project quality is guaranteed, and the course evaluation system is further perfect and scientific.

\section{CONCLUSION}

The trial and development of teaching reform and innovation in landscape design have efficiently improved students' abilities of landscape program design, computeraided drawing and expression, meanwhile, it also helps to improve students' abilities of post work and teamwork, students' comprehensive quality as well as teaching quality. Besides, it promotes the reform exploration in teaching patterns. This article conducts studies and summary on the reform and practice of experimental teaching so as to be referenced for the coming teaching reforms on the landscape design specialty.

\section{REFERENCES}

[1] Yu Konjian, Li Dihua, Landscape Design: Professional Subject and Education [M]. Beijing: China Architecture \& Building Press, 2003.

[2] Liu Binyi, Modern Landscape Layout and Design (Edition 2) [M] Nanjing: Southeast University Press, 2005.

[3] Li Kairan, Bases of Landscape Design [M].Shanghai: Shanghai People's Publishing House, 2006.

[4] Shan Wei, Construction, Studies and Development of Environmental Art Design [J], 2005(62): pp 149.

[5] Liang Limin, Development and Thought of Environmental Art Design Teaching [J]. Education and Vacation, 2006(5): pp 147-148. 